\title{
Híbridos de trifoliata como porta-enxertos para a laranjeira 'Valência'
}

\author{
Jorgino Pompeu Junior(1) e Silvia Blumer(2)
}

\begin{abstract}
(1)Agência Paulista de Tecnologia dos Agronegócios, Centro de Citricultura Sylvio Moreira, Caixa Postal 04, CEP $13490-970$ Cordeirópolis, SP. E-mail: jorgino@centrodecitricultura.br (2)Universidade de São Paulo, Escola Superior de Agricultura Luiz de Queiroz, Departamento de Fitopatologia e Nematologia Agrícola, Caixa Postal 09, CEP 13418-900 Piracicaba, SP. E-mail: blumer@esalq.usp.br
\end{abstract}

Resumo - O objetivo deste trabalho foi avaliar a produtividade e as características agronômicas de laranjeira 'Valência', enxertadas em porta-enxertos de híbridos de trifoliata (Poncirus trifoliata). A produção de frutos, a de sólidos solúveis totais por planta, as dimensões e a eficiência produtiva de copas de laranjeira 'Valência', enxertadas em 13 híbridos de trifoliata, cultivados sem irrigação, foram avaliados por períodos que variaram de três a oito anos. As plantas também foram avaliadas, visualmente, quanto à manifestação dos sintomas de tristeza (Citrus tristeza virus) e de declínio-dos-citros, e foi utilizado o teste diagnóstico "dot immunobinding assay" (DIBA), para deteç̧ão da ocorrência do declínio antes do aparecimento dos sintomas. As plantas tinham oito anos de idade, no início das avaliações. Verificou-se que o citrandarin 'Sunki' x 'English' induziu as maiores produções de frutos em oito colheitas, sem diferir significativamente do citrange 'Troyer'. Em três anos de análise, o citrandarin 'Sunki' x 'English', sem diferir dos citranges 'Troyer' e 'Carrizo', também induziu as maiores produções de frutos e sólidos solúveis por planta. O citrentin 'Clementina' x trifoliata, os citrandarins 'Cleópatra' x 'Swingle' (715) e (1.614), 'Cleópatra' x 'Rubidoux' (1.600) e 'Cleópatra' x 'Christian' induziram a formação de laranjeiras da cultivar Valência com alturas iguais ou inferiores a 2,5 m. Nenhuma das plantas apresentou sintomas de tristeza ou declínio-dos-citros. Foi constatada a incompatibilidade entre a cultivar Valência e o trangpur 'Cravo' x 'Carrizo'.

Termos para indexação: Poncirus trifoliata, citrandarin, citrange, declínio-dos-citros, nanismo, trangpur, tristeza-dos-citros.

\section{Trifoliate hybrids as rootstocks for sweet orange 'Valência'}

\begin{abstract}
The objective of this work was to evaluate the productivity and agronomic traits of 'Valência' sweet orange tree budded onto trifoliate (Poncirus trifoliata) hybrids rootstocks. Fruit production, total soluble solids production per plant, canopy production efficiency and dimensions of 'Valência' sweet orange trees budded onto 13 trifoliate hybrids, culivated under nonirrigation conditions, were evaluated in periods ranging from three to eight years. Plants were also visually evaluated for symptoms of citrus blight and tristeza (Citrus tristeza virus) diseases, and the dot immunobinding assay (DIBA) test was used for detecting blight disease before the development of its symptoms. Plants were eight years old at the evaluation beginning. Trees on 'Sunki' x 'English' citrandarin and 'Troyer' citrange produced the highest cumulative yields in eight crops. In a three-year period, 'Sunki' x 'English" and 'Troyer' and 'Carrizo' induced the highest fruit yields and soluble solids per tree. The citrentin 'Clementina' x trifoliate, and the citrandarins 'Cleopatra' x 'Swingle' (715) and (1.614), 'Cleopatra' x 'Rubidoux' (1.600) and 'Cleopatra' x 'Christian' induced the formation of the smallest 'Valência' trees with heights below $2.5 \mathrm{~m}$. None of the trees showed symptoms of tristeza or blight disease. Trees on trangpur 'Cravo' x 'Carrizo' showed bud-union-ring symptom of incompatibility.
\end{abstract}

Index terms: Poncirus trifoliata, citrandarin, citrange, citrus blight, dwarfism, trangpur, tristeza disease.

\section{Introdução}

Desde a década de 1960, o limão 'Cravo' é o principal porta-enxerto da citricultura paulista (Pompeu Junior et al., 2004). Apesar de suas excelentes características agronômicas, com destaque para a resistência à seca e a indução de produção precoce, o 'Cravo' é suscetível ao declínio (Rodriguez et al., 1979) e à morte-súbita-dos-citros (Bassanezi et al., 2003). Essas enfermidades causam a perda de plantas e a redução na produção, encarecem os tratos culturais e encurtam a vida útil dos pomares. É imprescindível, portanto, a seleção de novos porta-enxertos, tolerantes aos principais fatores abióticos e bióticos limitantes à citricultura paulista. Além disso, é importante que porta-enxertos modernos induzam a formação de plantas 
de pequeno porte, pois plantas nanicas geralmente apresentam maior eficiência produtiva (quilograma de frutos por metro cúbico de copa), permitem elevadas densidades de plantio e possibilitam maiores produções por hectare. Em plantas com baixo porte, as inspeções e controle de pragas e doenças também são realizados com maior eficiência, o que resulta na redução do uso de defensivos e em menores impactos ambientais. Em médio prazo, as plantas de porte baixo facilitariam a implantação da colheita mecânica das frutas destinadas às indústrias de suco.

Um dos métodos para a obtenção de plantas nanicas é a utilização de porta-enxertos nanicantes, entre os quais os citrandarins, que são híbridos de microtangerinas como a 'Sunki' [Citrus sunki (Hayata) hort. ex Tan.] ou a tangerina 'Cleópatra' (C. reshni hort. ex Tan.), com trifoliata (Poncirus trifoliata Raf.). Nesses híbridos, pretende-se reunir as qualidades das tangerinas como tolerância ao declínio, ao viroide da exocorte e a solos calcários, às qualidades do trifoliata como a imunidade à tristeza, a resistência à gomose e ao frio e a indução de plantas nanicas. Os citrandarins são utilizados em diversos países: na África do Sul, 'Cleópatra' $\mathrm{x}$ trifoliata (C. reshni hort. ex Tan. x P. trifoliata Raf.) cv. X-639; Estados Unidos, 'Changsha' x 'English' large (C. reticulata Blanco x $P$. trifoliata Raf.) $\mathrm{cv}$. US-815, 'Sunki' x 'Benecke' [C. sunki (Hayata) hort. ex Tan. x $P$. trifoliata] cv. US-812, e 'Cleópatra' x 'Flying Dragon' (US-897) [C. reshni hort. ex Tan. $\mathrm{x} P$. trifoliata var. monstrosa (T. Ito) Swingle cv. US-897; e, na Espanha, 'Cleópatra' x trifoliata (Forner \& Alcaide-5) e (F\&A-13). Para uso no Estado de São Paulo, foram selecionados os citrandarins 'Changsha' x 'English' small e 'Sunki' x 'Benecke' (Pompeu Junior et al., 2002).

A seleção de outros citrandarins - indutores de produção e qualidade de frutos desejáveis e tolerantes a fatores bióticos e abióticos - é altamente relevante para a citricultura paulista. Assim, Blumer \& Pompeu Junior (2005) publicaram os resultados referentes às quatro primeiras colheitas e à resistência a Phytophthora sp. dos materiais usados no presente trabalho. No entanto, por se tratar de cultura perene e, tendo em vista que algumas doenças relacionadas aos porta-enxertos, como declínio e incompatibilidades, podem exigir dez ou mais anos para se manifestar, é importante que se dê continuidade a essas avaliações.

O objetivo deste trabalho foi avaliar, ao longo de oito anos, o comportamento de laranjeiras adultas da cultivar Valência enxertadas em híbridos com trifoliata.

\section{Material e Métodos}

O experimento foi instalado em fevereiro de 1988, em Itirapina, SP, com clima Cwa (Setzer, 1966), em Latossolo Vermelho-Amarelo, de textura arenosa, no espaçamento $7,5 \times 4,2 \mathrm{~m}$, conduzido sem irrigação. Foram avaliados os seguintes porta-enxertos (os números entre parênteses referem-se ao número de registro no Banco Ativo de Germoplasma do Instituto Agronômico): os citranges [Citrus sinensis (L). Osb. $\mathrm{x}$ Poncirus trifoliata Raf.] das cultivares Troyer (385) e Carrizo (387); os citrandarins (Citrus reshni hort. ex Tan. x P. trifoliata Raf.) 'Cleópatra' x 'English' (710), 'Cleópatra' x 'Christian' (712), 'Cleópatra' x 'Swingle' (715), (1.587) e (1.614), 'Cleópatra' x trifoliata (1.574), 'Cleópatra' x 'Rubidoux' (1.600) e (1.660); o citrandarin [C. sunki (Hayata) hort. ex Tan. x P. trifoliata Raf.] 'Sunki' x 'English' (1.628); o citrentin ( $C$. clementina hort. ex Tan. x $P$. trifoliata Raf.) 'Clementina' x trifoliata (1.615); e o trangpur [C. limonia Osb. x C. sinensis (L.) Osb. x P. trifoliata Raf.)] 'Cravo' x 'Carrizo' (717).

Como copa, foi utilizada a laranjeira 'Valência' [C. sinensis (L.) Osb.], clone nucelar que, por ocasião do planejamento do experimento em 1986, era a terceira copa mais importante da citricultura paulista (Pompeu Junior et al., 2004). Outro fator que contribuiu para a seleção dessa cultivar foi a ausência de relatos de sua incompatibilidade com outros porta-enxertos, exceto com o limão 'Rugoso' (C. jambhiri Lush.) (Bridges \& Youtsey, 1968). A utilização da larangeira 'Pêra' [C. sinensis (L.) Osb.], a principal copa da citricultura, poderia resultar na ocorrência de incompatibilidade com os porta-enxertos (Pompeu Junior, 2005), o que prejudicaria a interpretação dos resultados.

Os porta-enxertos foram avaliados quanto à: produção de frutos, no período 1996 a 2003; produção de sólidos solúveis por planta (Di Giorgi et al., 1990), em 2001, 2002 e 2003; a dimensão das plantas - raio da copa (R) e altura da planta (H) -, em 2000, 2001 e 2004; e eficiência produtiva das copas, obtida pelo quociente das produções pelo volume das copas, de acordo com a fórmula $\mathrm{V}=2 / 3 \pi \mathrm{R}^{2} \mathrm{H}$ (Mendel, 1956), em 1999, 2000 e 2003. As plantas foram avaliadas, visualmente, quanto à manifestação dos sintomas de tristeza e de declínio dos citros. Utilizou-se o teste diagnóstico "dot immunobinding assay" (DIBA), para detectar a proteína $12 \mathrm{kD}$, associada à ocorrência do declínio (Derrick et al., 1992). 
O delineamento estatístico foi o de blocos ao acaso, com uma planta por parcela e dez repetições. Os dados foram submetidos à análise de variância, e as médias foram comparadas pelo teste de Tukey, a 5\% de probabilidade, tendo-se considerado a ocorrência de parcelas perdidas, em três tratamentos, com uso do SAS (SAS Institute, 1995).

\section{Resultados e Discussão}

A Tabela 1 mostra as produções médias de frutos das laranjeiras de 1996 a 2003.

O citrandarin 'Sunki' x 'English' foi o mais produtivo em cada uma das avaliações e no total das oito colheitas computadas no período 1996-2003. O citrange 'Troyer' foi o segundo porta-enxerto mais produtivo nesse período, sem diferença significativa do citrandarin 'Sunki' x 'English', em sete das oito colheitas e no total produzido no período. O citrange 'Carrizo' não diferiu do 'Troyer' e foi o terceiro porta-enxerto mais produtivo. $\mathrm{O}$ desempenho dos citranges 'Troyer' e 'Carrizo' mostrou que esses porta-enxertos são indutores de produções tardias, já que eles haviam ocupado as últimas posições no quinquênio 1991/1995 (Blumer \& Pompeu Junior, 2005).

Os citrandarins 'Cleópatra' x 'English', 'Cleópatra' x trifoliata e 'Cleópatra' x 'Rubidoux' (1.660) ocuparam a quarta, quinta e sexta posições, respectativamente, de 1996-2003, com diferenças estatisticamente significativas do citrandarin 'Sunki' x 'English'.

O citrandarin 'Cleópatra' x 'Swingle' (715) e o trangpur 'Cravo' x 'Carrizo' posicionaram-se em oitavo e nono lugares no conjunto das oito colheitas. $\mathrm{O}$ trangpur
'Cravo' x 'Carrizo', que havia sido o quinto porta-enxerto mais produtivo no período 1991-1995 (Blumer \& Pompeu Junior, 2005), mostrou ser incompatível com a laranjeira 'Valência', pela constatação, em 2002, de anel de goma na linha de enxertia, responsável por alterações na nutrição das plantas e consequente redução na produção de frutos.

A comparação dos porta-enxertos com os mesmos parentais revelou que os irmãos germanos 'Cleópatra' x 'Rubidoux' (1.660) e (1.600) e 'Cleópatra' x 'Swingle' (715), (1.587) e (1.614) não diferiram significativamente entre si.

$\mathrm{Na}$ avaliação de frutos e de sólidos solúveis por planta, em 2001, 2002 e 2003 (Tabela 2), o citrandarin 'Sunki' x 'English', apesar de não ter diferido significativamente dos citranges 'Troyer' e 'Carrizo', induziu as maiores produções de frutos e de sólidos solúveis, seguidos do citrandarin 'Cleópatra' x 'English', que foi inferior somente na produção de frutos. Os citrandarins 'Cleópatra' x 'Rubidoux' (1.660) e (1.600) não diferiram entre si, assim como os irmãos 'Cleópatra' x 'Swingle' (1.587), (715) e (1.614).

Não foram constatadas diferenças significativas entre as médias das eficiências produtivas nos anos de 1999, 2000 e 2003.

Os dados médios da altura, diâmetro e volume das copas, em março de 2004, quando o experimento tinha 16 anos de idade, estão apresentados na Tabela 3.

O citrandarin 'Cleópatra' x 'Christian' induziu a formação de plantas com a menor altura, com média de 1,9 m, e os híbridos 'Clementina' x trifoliata, 'Cleópatra' x 'Swingle' (715), 'Cleópatra' x 'Swingle' (1.614), 'Cleópatra' x 'Rubidoux' (1.600) e 'Cravo' x 'Carrizo'

Tabela 1. Produções médias anuais de frutos (quilograma por planta) de laranjeira 'Valência' enxertada em híbridos de trifoliata $^{(1)}$.

\begin{tabular}{|c|c|c|c|c|c|c|c|c|c|}
\hline Porta-enxerto & 1996 & 1997 & 1998 & 1999 & 2000 & 2001 & 2002 & 2003 & Média \\
\hline Sunki x English' & $88,4 a$ & $96,5 \mathrm{a}$ & $72,0 \mathrm{a}$ & $141,8 \mathrm{a}$ & $78,9 \mathrm{a}$ & $156,1 \mathrm{a}$ & $154,6 \mathrm{a}$ & $95,2 \mathrm{a}$ & $110,4 \mathrm{a}$ \\
\hline 'Troyer' & $85,5 \mathrm{a}$ & $68,6 a b c$ & $48,4 \mathrm{abc}$ & $122,6 a b$ & $31,4 \mathrm{bcd}$ & $136,0 \mathrm{ab}$ & $118,1 \mathrm{ab}$ & $70,8 \mathrm{ab}$ & $85,2 \mathrm{ab}$ \\
\hline 'Carrizo' & $70,9 \mathrm{ab}$ & $80,1 \mathrm{ab}$ & $51,5 \mathrm{abc}$ & $122,3 \mathrm{ab}$ & $38,8 \mathrm{bcd}$ & $135,0 \mathrm{ab}$ & $97,0 \mathrm{bc}$ & $54,8 \mathrm{abc}$ & $81,3 \mathrm{bc}$ \\
\hline 'Cleópatra' x 'English' & $64,1 \mathrm{ab}$ & $96,5 \mathrm{a}$ & $64,1 \mathrm{ab}$ & $114,0 \mathrm{ab}$ & $58,0 \mathrm{ab}$ & $86,7 \mathrm{~cd}$ & $114,0 \mathrm{ab}$ & $52,6 a b c$ & $81,2 \mathrm{bc}$ \\
\hline Cleópatra $x$ trifoliata & $63,0 \mathrm{ab}$ & $69,7 \mathrm{abc}$ & $57,7 \mathrm{ab}$ & $114,0 \mathrm{ab}$ & $59,2 \mathrm{ab}$ & $97,5 \mathrm{bc}$ & $95,2 \mathrm{bc}$ & $42,8 \mathrm{bcd}$ & $74,9 \mathrm{bcd}$ \\
\hline 'Cleópatra' x 'Rubidoux (1.660) & $55,3 \mathrm{ab}$ & $98,5 \mathrm{a}$ & $49,9 \mathrm{abc}$ & $96,5 \mathrm{bc}$ & $61,4 \mathrm{ab}$ & 61,2 cde & $76,9 \mathrm{bcd}$ & $56,0 \mathrm{abc}$ & 69,5 bcde \\
\hline 'Cleópatra x 'Swingle' (1.587) & $37,1 b$ & $71,5 \mathrm{abc}$ & $39,8 \mathrm{abc}$ & $81,7 \mathrm{bcd}$ & $48,6 \mathrm{bc}$ & 57,1 cde & $72,2 \mathrm{bcd}$ & $35,1 \mathrm{bcd}$ & $55,4 \mathrm{cdef}$ \\
\hline 'Cleópatra' x 'Swingle' (715) & $49,2 \mathrm{ab}$ & $67,5 \mathrm{abc}$ & $37,8 \mathrm{abc}$ & $66,8 \mathrm{cde}$ & $43,9 \mathrm{bcd}$ & 47,9def & $52,6 \mathrm{~cd}$ & $22,9 \mathrm{~cd}$ & $48,6 \mathrm{defg}$ \\
\hline 'Cravo x 'Carrizo' & $60,7 \mathrm{ab}$ & $50,6 b c$ & $34,4 \mathrm{abc}$ & $64,1 \mathrm{~cd}$ & $36,4 \mathrm{bcd}$ & 47,9def & $59,4 \mathrm{~cd}$ & $12,1 \mathrm{~cd}$ & 45,7 efg \\
\hline 'Cleópatra' x 'Rubidoux' (1.600) & $35,8 b$ & $55,9 \mathrm{bc}$ & $24,0 \mathrm{c}$ & $68,2 \mathrm{cde}$ & $45,9 \mathrm{bcd}$ & $37,7 \mathrm{ef}$ & $68,2 \mathrm{bcd}$ & $21,6 \mathrm{~cd}$ & 44,7 efg \\
\hline 'Cleópatra x 'Swingle' (1.614) & $32,4 b$ & $53,3 \mathrm{bc}$ & $33,7 \mathrm{bc}$ & $58,0 \mathrm{cde}$ & $27,7 \mathrm{~cd}$ & $22,4 \mathrm{ef}$ & $36,4 d$ & $16,2 \mathrm{~cd}$ & $35,0 \mathrm{fg}$ \\
\hline Clementina $\mathrm{x}$ trifoliata & $41,2 b$ & $47,2 \mathrm{bc}$ & $31,5 \mathrm{bc}$ & $40,5 \mathrm{e}$ & $25,5 \mathrm{~cd}$ & $26,1 \mathrm{ef}$ & $42,0 \mathrm{~d}$ & $13,5 \mathrm{~cd}$ & $33,4 \mathrm{fg}$ \\
\hline 'Cleópatra' x 'Christian' & $38,5 b$ & $37,1 \mathrm{c}$ & $25,6 \mathrm{c}$ & $42,5 \mathrm{de}$ & $17,5 \mathrm{~d}$ & $11,2 \mathrm{f}$ & $27,6 \mathrm{~d}$ & $3,4 \mathrm{~d}$ & $25,4 \mathrm{~g}$ \\
\hline DMS & 39,9 & 35,2 & 37,5 & 41,1 & 30,2 & 42,4 & 52,1 & 47,2 & 26,4 \\
\hline CV $(\%)$ & 46,6 & 32,6 & 54,9 & 30,6 & 42,8 & 39,4 & 43,0 & 80,5 & 42,5 \\
\hline
\end{tabular}

${ }^{(1)}$ Médias seguidas por letras iguais, nas colunas, não diferem entre si pelo teste de Tukey, a 5\% de probabilidade. 
Tabela 2. Produções médias de frutos (caixas de $40,8 \mathrm{~kg}$ por planta) e de sólidos solúveis por caixa (SScx) e por planta (SSpl), de laranjeira 'Valência' enxertada em híbridos de trifoliata ${ }^{(1)}$.

\begin{tabular}{|c|c|c|c|c|c|c|c|c|c|c|c|}
\hline \multirow[t]{3}{*}{ Porta-enxerto } & \multicolumn{3}{|c|}{2001} & \multicolumn{3}{|c|}{2002} & \multicolumn{3}{|c|}{2003} & \multicolumn{2}{|c|}{ Total } \\
\hline & Caixas & SScx & SSpl & Caixas & SScx & SSpl & Caixas & SScx & SSpl & Frutos & SSpl \\
\hline & & \multicolumn{2}{|c|}{--------(kg)------- } & \multicolumn{3}{|c|}{--------(kg)------- } & & \multicolumn{2}{|c|}{--------(kg)------ } & \multicolumn{2}{|c|}{------(kg por planta)-------- } \\
\hline Sunki x English & 3,8 & 2,36 & 9,0 & 3,8 & 2,10 & 8,0 & 2,3 & 2,50 & 5,8 & $405,9 \mathrm{a}$ & $22,8 \mathrm{a}$ \\
\hline 'Troyer' & 3,3 & 2,47 & 8,2 & 2,9 & 2,22 & 6,4 & 1,7 & 2,68 & 4,7 & $324,9 \mathrm{ab}$ & $19,3 \mathrm{ab}$ \\
\hline 'Carrizo' & 3,3 & 2,42 & 8,0 & 2,4 & 2,19 & 5,2 & 1,3 & 2,51 & 3,4 & $286,8 \mathrm{abc}$ & $16,6 \mathrm{abc}$ \\
\hline 'Cleópatra' x 'English' & 2,1 & 2,65 & 5,6 & 2,8 & 2,46 & 6,9 & 1,3 & 2,68 & 3,5 & $253,6 \mathrm{bc}$ & $16,0 \mathrm{abc}$ \\
\hline Cleópatra x 'Rubidoux (1.660) & 1,5 & 2,69 & 4,0 & 1,9 & 2,50 & 4,7 & 1,4 & 2,80 & 3,8 & $194,1 \mathrm{bcd}$ & $12,6 \mathrm{bcd}$ \\
\hline Cleópatra $\mathrm{x}$ trifoliata & 2,4 & 2,25 & 5,4 & 2,3 & 1,84 & 4,3 & 1,0 & 2,17 & 2,3 & $235,5 \mathrm{cde}$ & 11,9 bcde \\
\hline 'Cleópatra x 'Swingle' (1.587) & 1,4 & 2,68 & 3,8 & 1,8 & 2,30 & 4,1 & 0,9 & 2,73 & 2,3 & $164,4 \mathrm{cdef}$ & $10,2 \mathrm{cdef}$ \\
\hline 'Cleópatra x 'Swingle' (715) & 1,2 & 2,86 & 3,4 & 1,3 & 2,53 & 3,3 & 0,6 & 2,77 & 1,6 & 123,4 def & 8,2 defg \\
\hline 'Cleópatra' x 'Rubidoux' (1.600) & 0,9 & 2,49 & 2,3 & 1,7 & 2,46 & 4,1 & 0,5 & 2,45 & 1,3 & $127,5 \mathrm{def}$ & 7,7 defg \\
\hline 'Cravo x 'Carrizo' & 1,2 & 2,47 & 2,9 & 1,5 & 2,29 & 3,3 & 0,3 & 2,31 & 0,7 & $119,4 \mathrm{def}$ & 6,9 defg \\
\hline 'Clementina $\mathrm{x}$ trifoliata & 0,6 & 2,61 & 1,7 & 1,0 & 2,38 & 2,5 & 0,3 & 2,61 & 0,9 & $81,6 \mathrm{ef}$ & $5,0 \mathrm{efg}$ \\
\hline 'Cleópatra' x 'Swingle' (1.614) & 0,5 & 2,59 & 1,4 & 0,9 & 2,33 & 2,1 & 0,4 & 2,40 & 1,0 & $75,0 \mathrm{ef}$ & $4,5 \mathrm{fg}$ \\
\hline Cleópatra x Christian & 0,3 & 2,71 & 0,7 & 0,7 & 2,59 & 1,8 & 0,1 & $-(2)$ & - & $42,2 \mathrm{f}$ & $2,5 \mathrm{~g}$ \\
\hline DMS & & & & & & & & & & 41,8 & 2,4 \\
\hline CV $(\%)$ & & & & & & & & & & 22,4 & 22,2 \\
\hline
\end{tabular}

${ }^{(1)}$ Médias seguidas por letras iguais, nas colunas, não diferem entre si pelo teste de Tukey, a 5\% de probabilidade. ${ }^{(2)}$ Dados não coletados.

Tabela 3. Altura, diâmetro e volume das copas de laranjeira 'Valência', enxertada em híbridos de trifoliata, medidos aos 16 anos de idade (março de 2004).

\begin{tabular}{llll}
\hline Porta-enxerto & Altura & $\begin{array}{c}\text { Diâmetro } \\
\text {----------(m)-------- }\end{array}$ & $\begin{array}{c}\text { Volume } \\
\left(\mathrm{m}^{3}\right)\end{array}$ \\
\hline 'Sunki x English' & $3,6 \mathrm{a}$ & $3,6 \mathrm{a}$ & $25,2 \mathrm{a}$ \\
'Carrizo' & $3,5 \mathrm{a}$ & $3,4 \mathrm{ab}$ & $21,9 \mathrm{ab}$ \\
'Troyer' & $3,3 \mathrm{ab}$ & $3,1 \mathrm{abcd}$ & $17,2 \mathrm{bc}$ \\
'Cleópatra' x trifoliata & $2,9 \mathrm{bc}$ & $3,2 \mathrm{abc}$ & $16,0 \mathrm{bc}$ \\
'Cleópatra' x 'English' & $2,8 \mathrm{bc}$ & $3,1 \mathrm{abcd}$ & $14,4 \mathrm{~cd}$ \\
'Cleópatra' x 'Swingle' (1.587) & $2,7 \mathrm{~cd}$ & $2,8 \mathrm{cdf}$ & $11,9 \mathrm{cde}$ \\
Cleópatra' x 'Rubidoux (1.660) & $2,6 \mathrm{cde}$ & $3,0 \mathrm{bce}$ & $12,7 \mathrm{cde}$ \\
'Clementina' x trifoliata & $2,5 \mathrm{cdef}$ & $2,5 \mathrm{efg}$ & $9,0 \mathrm{def}$ \\
'Cleópatra' x 'Swingle' (715) & $2,3 \mathrm{defg}$ & $2,6 \mathrm{defg}$ & $8,5 \mathrm{def}$ \\
'Cleópatra' x 'Rubidoux' (1.600) & $2,3 \mathrm{defg}$ & $2,6 \mathrm{defg}$ & $8,5 \mathrm{def}$ \\
Cleópatra' x 'Swingle' (1.614) & $2,2 \mathrm{efg}$ & $2,4 \mathrm{fg}$ & $7,3 \mathrm{ef}$ \\
Cravo' x 'Carrizo & $2,1 \mathrm{fg}$ & $2,4 \mathrm{fg}$ & $6,5 \mathrm{ef}$ \\
Cleópatra' x 'Christian' & $1,9 \mathrm{~g}$ & $2,1 \mathrm{~g}$ & $4,5 \mathrm{f}$ \\
\hline DMS & 0,43 & 0,53 & 6,30 \\
CV (\%) & 10,2 & 11,9 & 32,4 \\
\hline
\end{tabular}

${ }^{(1)}$ Médias seguidas por letras iguais, nas colunas, não diferem entre si pelo teste de Tukey, a 5\% de probabilidade.

induziram a formação de plantas com alturas iguais ou inferiores a 2,5 m, o que indica que são porta-enxertos nanicantes. $\mathrm{O}$ demais porta-enxertos foram considerados como seminanicantes, segundo a classificação proposta por W. Bitters (Barry, 1993), por terem proporcionado plantas com altura inferior a $4 \mathrm{~m}$.

Os porta-enxertos que proporcionaram o menor diâmetro de copa e que, teoricamente, possibilitariam maior adensamento de plantio, foram 'Clementina' x trifoliata, 'Cleópatra' x 'Swingle' (1.614), 'Cravo' x 'Carrizo' e 'Cleópatra' x 'Christian'; este último foi o que induziu a formação das menores plantas, com diâmetro médio de 2,1 m.
As plantas que apresentaram o maior volume de copa $\left(25,2 \mathrm{~m}^{3}\right)$ estavam enxertadas no citrandarin 'Sunki' $\mathrm{x}$ 'English'. O menor volume de copa $\left(4,5 \mathrm{~m}^{3}\right)$ foi induzido pelo citrandarin 'Cleópatra' x 'Christian' (Tabela 3).

Até março de 2004, quando as plantas tinham 16 anos de idade, não foram constatados sintomas de suscetibilidade dos porta-enxertos ao vírus da tristeza. Esses resultados eram esperados, uma vez que os parentais são tolerantes ou imunes a esse vírus, mas a ocorrência de híbridos sensíveis também era possível, já que, de acordo com Forner \& Forner-Giner (2002), híbridos do citrange 'Troyer' com tangerina 'Cleópatra' e os híbridos desta ou do citrange 'Troyer' com $P$. trifoliata podem ser tolerantes ou não à tristeza.

Até março de 2004, nenhuma das plantas apresentou sintomas do declínio-dos-citros. Também foram negativos os resultados dos testes realizados nesse mesmo mês, quanto à presença da proteína $12 \mathrm{kD}$, precursora dos sintomas dessa anomalia (Derrick et al., 1992). Assim, os porta-enxertos podem ser considerados não suscetíveis ao declínio-dos-citros até os 16 anos de idade.

Em decorrência do definhamento de algumas plantas, enxertadas no trangpur 'Cravo' x 'Carrizo', e da constatação da presença, em junho de 2002, de uma linha de depressão na região da enxertia, foi retirada a casca dessa região de três plantas. Em duas, foram encontradas pontuações necróticas e depressões no lenho, semelhantes às relatadas por Nauriyal et al. (1958), consideradas indicadoras de incompatibilidade entre copa e porta-enxerto.

Em agosto de 2004, foi verificado que todas as plantas dessa combinação estavam depauperadas, e que $80 \%$ 
delas apresentavam sinais de incompatibilidade na região da enxertia. Essa constatação representa mais um percalço na seleção de novos porta-enxertos, pois somente eram conhecidas as incompatibilidades do trangpur 'Cravo' x 'Carrizo' (717) com a laranja 'Pêra' e com o tangor Murcott (C. reticulata Bl. X C. sinensis Osb.) (Pompeu Junior, 2005).

\section{Conclusões}

1. O citrandarin 'Sunki' x 'English' e o citrange 'Troyer' são os dois porta-enxertos mais produtivos, entre os 13 híbridos de trifoliata avaliados.

2. O citrandarin 'Sunki' x 'English' e os citranges 'Troyer' e 'Carrizo' induzem a produção de frutos com altos teores de sólidos solúveis.

3. Os citrandarins 'Clementina' $x$ trifoliata, 'Cleópatra' x 'Swingle' (715) e (1.614), 'Cleópatra' x 'Rubidoux' (1.600) e 'Cleópatra' x 'Christian' induzem a formação de laranjeiras de porte pequeno.

4. Os citrandarins são tolerantes à tristeza e ao declínio-dos-citros.

5. O trangpur 'Cravo' x 'Carrizo' é incompatível com a laranjeira 'Valência'.

\section{Agradecimentos}

À Fundação de Amparo à Pesquisa do Estado de São Paulo e ao Conselho Nacional de Desenvolvimento Científico e Tecnológico, pelo suporte financeiro; à Coordenação de Aperfeiçoamento de Pessoal de Nível Superior, pela concessão de bolsa; ao United States Horticultural Research Laboratory, Fort Pierce, Florida, pela cessão dos porta-enxertos; às Fazendas Reunidas Raio de Sol, pela cessão da área e manutenção do experimento; ao Fundo de Defesa da Citricultura, pelo empréstimo de veículo.

\section{Referências}

BARRY, G.H. Rootstocks for tree size control. In: WORLD CONGRESS OF THE INTERNATIONAL SOCIETY OF CITRUS NURSERYMEN, 4., 1993, Johannesburg. Proceedings. Johannesburg: The South African Citrus Nurserymen's Association, 1993. p.367-369.
BASSANEZI, R.B.; BERGAMIN FILHO, A.; AMORIM, L.; GIMENES-FERNANDES, N.; GOTTWALD, T.R.; BOVÉ, J.M. Spatial and temporal analyses of citrus sudden death as a tool to generate hypotheses concerning its etiology. Phytopathology, v.93, p.502-512, 2003.

BLUMER, S.; POMPEU JUNIOR, J. Avaliação de citrandarins e outros híbridos de trifoliata como porta-enxertos para citros em São Paulo. Revista Brasileira de Fruticultura, v.27, p.264-267, 2005.

BRIDGES, G.D.; YOUTSEY, C.O. Further studies of the bud-union abnormality of rough lemon rootstocks with sweet orange scions. In: CONFERENCE OF THE INTERNATIONAL ORGANIZATION OF CITRUS VIROLOGISTS, 4., 1968, Gainesville. Proceedings. Gainesville: International Organization of Citrus Virologists, 1968. p.236-239.

DERRICK, K.S.; BARTHE, G.A.; HEWITT, B.G.; LEE, R.F.; ALBRIGO, L.G.; IREY, M.S. Detection of citrus blight by serological assays. Florida State Horticultural Society, v.105, p.26-28, 1992.

DI GIORGI, F.; IDE, B.Y.; DIB, K.; MARCH, R.J.; TRIBONI, H.D.; WAGNER, R.L. Contribuição ao estudo do comportamento de algumas variedades de citros e suas implicações agroindustriais. Laranja, v.11, p.567-612, 1990.

FORNER, J.B.; FORNER-GINER, M.A. Programa de melhoramento de porta-enxertos na Espanha. In: SEMINÁRIO INTERNACIONAL DE CITROS: MELHORAMENTO, 7., 2002, Bebedouro. Anais. Bebedouro: Estação Experimental de Citricultura de Bebedouro, 2002. p.82-95.

MENDEL, K. Rootstock-scion relationships in Shamouti trees on light soil. Ktavim, v.6, p.35-60, 1956.

NAURIYAL, J.P.; SHANNON, L.M.; FROLICH, E.F. Eureka lemon-trifoliate orange: incompatibility. Journal of the American Society for Horticultural Science, v.72, p.273-283, 1958.

POMPEU JUNIOR, J. Porta-enxertos. In: MATTOS JÚNIOR, D. de; DE NEGRI, J.D.; PIO, R.M.; POMPEU JUNIOR, J. (Ed.). Citros. Campinas: Instituto Agronômico; Fundag, 2005. p.61-104.

POMPEU JUNIOR, J.; LARANJEIRA, F.F.; BLUMER, S. Laranjeiras 'Valência' enxertadas em híbridos de trifoliata. Scientia Agricola, v.59, p.93-97, 2002.

POMPEU JUNIOR, J.; SALVA, R.; BLUMER, S. Copas e porta-enxertos nos viveiros de mudas cítricas do Estado de São Paulo. Laranja, v.25, p.413-422, 2004.

RODRIGUEZ, O.; ROSSETTI, V.; MULLER, G.W.; MOREIRA, C.S.; PRATES, H.S.; NEGRI, J.D. de; GREVE, A. Declínio de plantas cítricas em São Paulo. In: CONGRESSO BRASILEIRO DE FRUTICULTURA, 5., 1979, Pelotas. Anais. Pelotas: Sociedade Brasileira de Fruticultura, 1979. p.927-932.

SAS INSTITUTE. SAS user's guide. Cary: SAS Institute, 1995.

SETZER, J. Atlas climático e ecológico do Estado de São Paulo. São Paulo: Comissão Interestadual da Bacia Paraná-Uruguai, 1966. 61p.

Recebido em 9 de fevereiro de 2009 e aprovado em 25 de junho de 2009 